\title{
Indirect Land Use Change Debate: What Did We Learn?
}

\author{
Simla Tokgoz • David Laborde
}

Published online: 29 June 2014

(C) Springer International Publishing AG 2014

\begin{abstract}
In recent years, many public policies and regulations have supported the biofuel expansion in many countries. One of the main reasons for this support was concern about the environment, since biofuels, when used in place of traditional fossil fuel-based transportation fuels, lead to lower greenhouse gas (GHG) emissions. However, this argument was contradicted with the discussion on indirect land use change (ILUC) from biofuel expansion, leading to higher GHG emissions. Acknowledging this debate, we present a literature review focusing on the recent studies on ILUC and GHG emissions related to the biomass production and processing. We provide a summary of the main issues in this debate that focus on the impact of model characteristics on the GHG emissions computation, specifically those triggered by land use change.
\end{abstract}

Keywords Greenhouse gas emissions $\cdot$ Indirect land use change $\cdot$ Biofuels $\cdot$ Ethanol $\cdot$ Biodiesel

\section{Introduction}

Public policies and regulations that have triggered and supported the biofuel expansion in recent years have been motivated by several factors such as diversification of energy supply and support for rural incomes. Environmental concerns have also been a key justification since biofuels, when used in place of traditional fossil fuel-based transportation fuels, lead to lower greenhouse gas (GHG) emissions. However, this

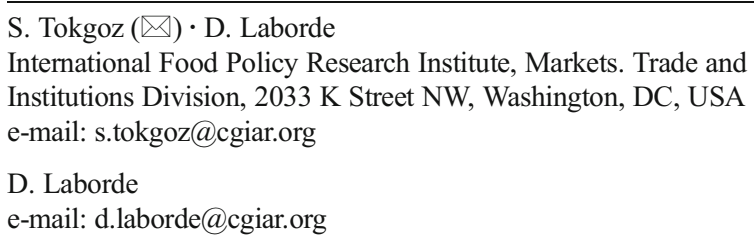

argument was countered in recent years with the discussion on indirect land use change (ILUC) leading to net higher GHG emissions $[1,2]$.

Biofuels affect GHG emissions in two opposite directions. First, by displacing an energy-equivalent amount of fossil fuels, they reduce GHG emissions (for example, when ethanol is used in vehicles in place of gasoline). Second, they lead to ILUC and increase GHG emissions through the release of carbon sequestered on land converted to biofuel production or by release of carbon stored in soils/vegetation (e.g. deforestation, peatland destruction). This change happens when, through the impact of higher crop prices caused by higher biofuel demand, demand for agricultural crop area increases either for traditional crops or for dedicated energy crops. If the second effect is larger than the first, the environmental benefits of biofuels are called into question. Thus, it is crucial that ILUC and GHG accounting are done correctly. Khanna and Chen [3] note various factors in accounting for this net effect. One factor is how much fossil energy inputs are used directly over the lifecycle of biofuels production. Another factor is the change in soil carbon as land is directly converted to crop production [3]. As Khatiwada et al., summarizing the vast literature on this issue, put it: ILUC is critical due to the possibility that these GHG emissions might counter their benefits from biofuels substituting for fossil fuels [4].

It should also be noted that use of agricultural inputs, such as fertilizer, also lead to GHG emissions through higher $\mathrm{N}_{2} \mathrm{O}$ emissions. Rice and livestock productions generate $\mathrm{CH}_{4}$. Thus, the direct and indirect emissions balance from agriculture is a complicated issue that requires careful analysis.

The ILUC implications from biofuels expansion has impacted the debate surrounding biofuels as well as the policy design. Therefore, there are many studies dedicated to simulating the magnitude of ILUC and the related GHG emissions from biofuels expansion. These studies generally focus on implications of legislative processes and rely on the use of 
various analytical tools, such as partial equilibrium (PE), computable general equilibrium (CGE), or linear programming models. This debate centers on computing the magnitude of the direct and indirect land use change from a shock relative to a baseline, where land use change will take place, the short-run versus the long-run effects of the shock (time frame for computing the GHG emissions). The factors that condition the answer to these questions depend on the biofuel pathways (in the marketplace and included in the model), criteria used for assessment of ILUC (through lifecycle GHG emission savings relative to a baseline or through carbon intensity computation), how biofuel demand is met (through domestic production or imports of biofuels, and if through domestic production, whether through domestic feedstocks or imported feedstocks).

Khanna and Zilberman also give a detailed list of the pathways through which biofuels expansion impacts land resources [5]. On the demand side, they list any policy shock, energy price shock, and vehicle fleet composition, among others. On the supply side, they list yield of biofuel feedstocks, co-products, land productivity at the intensive and extensive margin, substitution of land across uses, and technology.

Zilberman et al. also note the importance of including ILUC in GHG emission estimates since the market adjustments that occur due to biofuel expansion need to be considered [6]. In this regard, they provide four additional indirect effects to be analyzed: two regarding the final and intermediate demand for agricultural products, indirect food consumption effect, indirect co-product effect; and two regarding the oil markets, indirect fuel use change and indirect fuel supply change. The latter effects are directly linked to the carbon leakage issue of the policy by reducing the expected gains from a reduction in fossil fuel consumption when additional biofuel supply leads to a decrease in fossil fuel prices, creating a demand "rebound" effect. This leakage can be domestic or international and its magnitude depends highly on the policy instruments used to foster biofuel consumption, e.g. tax credit or mandate [7]. This effect, also measured by the "net oil displacement factor" (NODF) $)^{1}$ in Rajagopal and Plevin [8], is weakly marginal since the estimated range in the literature goes from $50 \%$ to $75 \%$ on average (see [8] Fig. 2, [7] Table 1, or [9] page 58).

Acknowledging this phenomenon, we focus our literature review in this article on the emissions related to the biomass production and processing. We provide a summary of the latest work (our list is not exhaustive) and the issues in this debate that focus on the impact of model characteristics on the GHG emissions computation, specifically those triggered by land use change. Table 1 provides a summary of the models

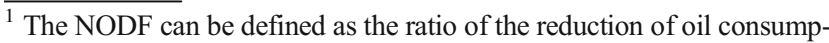
tion to the increase in global biofuel consumption.
}

discussed in this review. Our main question is how do the various ways to model the land use change (Section 2), handle uncertainty (Section 3), and account for GHG emissions (Section 4) affect the policy implications from the different models (Conclusions)?

\section{Land Use Change}

As discussed previously, GHG emissions from direct and indirect land use change are critical due the possibility that these GHG emissions might counter their benefits from biofuels substituting for fossil fuels. There are three main factors that condition the answer to this question. First is the size and the location of land use change (i.e., if a new crop area comes into production or if crop area reallocation takes place). Second is the type of feedstocks being used in the biofuel pathways. Third is the trade policy regime for the biofuels and the feedstocks used for biofuels production. The literature includes various simulation models that incorporate these characteristics and the simulation results depend on these model characteristics. In this section, we will discuss these three characteristics.

\section{Spatial Explicitness of Land Use in the Model}

The most critical component for computation of GHG emissions is the indirect and direct land use change taking place and how models incorporate this change. A higher level of spatial explicitness allows models to determine correctly where production takes place. This is crucial to determine the GHG emissions since it allows modelers to determine how much crop area reallocation takes place, how much land is converted to crop production, and which category of land is converted to crop production. Khanna and Zilberman also provide a discussion on existing modeling approaches and key results [5]. In this subsection, we present three models that use different approaches in terms of land use representation (modeling, level of aggregation, and scope) to illustrate the current literature.

The study by Laborde and Valin uses a global CGE model, MIRAGE-BIOF, ${ }^{2}$ to analyze the implications of the European Union Renewable Energy Directive (EU RED) under different assumptions regarding the future evolution of biodiesel and ethanol shares in the EU transportation fuel consumption [10•]. MIRAGE-BIOF is a CGE model, with a detailed agricultural sector module. It updates and significantly modifies the GTAP database, refines agricultural production functions, and includes land use substitution and expansion. It also differentiates among different land use types as well as includes detailed regional disaggregation,

\footnotetext{
${ }^{2}$ Also used by Laborde, 2011.
} 
Table 1 List of models reviewed

\begin{tabular}{|c|c|c|c|c|c|c|c|c|c|}
\hline & \multirow[t]{2}{*}{ Model } & \multirow[t]{2}{*}{ Countries } & \multicolumn{7}{|c|}{ Scenarios } \\
\hline & & & $\begin{array}{l}\text { US } \\
\text { RFS2 }\end{array}$ & $\begin{array}{l}\text { EU RED + } \\
\text { NREAP }\end{array}$ & $\begin{array}{l}\text { Biomass } \\
\text { technology }\end{array}$ & $\begin{array}{l}\text { Cellulosic } \\
\text { feedstock } \\
\text { storage cost }\end{array}$ & $\begin{array}{l}\text { Carbon } \\
\text { prices/tax }\end{array}$ & $\begin{array}{l}\text { Cellulosic } \\
\text { biofuel } \\
\text { producers } \\
\text { tax credit }\end{array}$ & $\begin{array}{l}\text { Biofuel } \\
\text { tax credit }\end{array}$ \\
\hline Sarica and Tyner (2013) & US EPA MARKAL & US only & $\mathrm{X}$ & & $X$ & & & & \\
\hline $\begin{array}{l}\text { Laborde and Valin } \\
\text { (2012) }\end{array}$ & MIRAGE-BIOF & Global & & $X$ & & & & & \\
\hline $\begin{array}{l}\text { Beach, Zhang, and } \\
\text { McCarl (2012) }\end{array}$ & FASOMGHG & US only & & & & $\mathrm{X}$ & $X$ & & \\
\hline $\begin{array}{l}\text { Chen, Huang, Khanna } \\
\text { (2012) }\end{array}$ & BEPAM & US Only & $\mathrm{X}$ & & & & $\mathrm{X}$ & $\mathrm{X}$ & \\
\hline $\begin{array}{l}\text { Kauffman and Hayes } \\
\text { (2013) }\end{array}$ & Specific PE model & US only & & & & & & & $X$ \\
\hline $\begin{array}{l}\text { Drabik and de Gorter } \\
\quad(2011)\end{array}$ & $\begin{array}{l}\text { PE model of } \\
\text { the fuel/biofuel } \\
\text { sector NO } \\
\text { LAND USE }\end{array}$ & US and EU & $\mathrm{X}$ & & & & & & $\mathrm{X}$ \\
\hline $\begin{array}{l}\text { Huang, Khanna, Onal, } \\
\text { Chen (2011) }\end{array}$ & BEPAM & US only & $\mathrm{X}$ & & & & $\mathrm{X}$ & & $\mathrm{X}$ \\
\hline $\begin{array}{l}\text { Rajagopal and Plevin } \\
\text { (2011) }\end{array}$ & $\begin{array}{l}\text { PE model for } \\
\text { global oil markets, } \\
\text { MC approach }\end{array}$ & Global & $\mathrm{X}$ & & & & & & \\
\hline $\begin{array}{l}\text { Mosnier, Havlik, Valin, } \\
\text { Baker, Murray, Feng, } \\
\text { Obersteiner, McCarl, } \\
\text { Rose and Schneider } \\
\text { (2013) }\end{array}$ & GLOBIOM & Global & $\mathrm{X}$ & & & & & & \\
\hline Laborde (2011) & MIRAGE-BIOF & Global & & $\mathrm{X}$ & & & & & \\
\hline
\end{tabular}

i.e. Agro-Ecological Zone (AEZ). The model allows for land use expansion into different activities (different crops, pasture, forestry) and land covers at the AEZ level using a nested-CET approach. This approach is conceptually similar to other CGEs, in particular the GTAP-Biof, but differs in one key aspect: a non-isoelastic land supply for anthropic activities at the AEZ level allowing extension into pristine environment when land rents increase [11]. The study shows the significant impact of EU RED on global land use, since the intensive margin response remains limited in terms of contribution to production increase. The land use impact takes place primarily outside the EU, with most of the crop production from savannah and grasslands. As they show, the closure assumption regarding the potential competition between cropland and pasture land plays an important role: allowing substitution effects and intensification in the livestock sectors allow most of additional cropland $(60-70 \%)$ to come from grassland-type land cover, leading to carbon emissions. In the scenario of biodiesel expansion within EU member states' National Renewable Energy Action Plan (NREAP), carbon emissions are even larger due to the expansion of palm oil in Southeast Asia and larger extension of soybean production in Latin America. Since EU RED includes a significant share of biodiesel, different from other countries' biofuel targets, the MIRAGE-BIOF scenario analyses are useful to compare with U.S. policy scenarios to highlight the importance of feedstock and biofuel mixes on ILUC and GHG emissions.

Beach et al. [12•] use the FASOMGHG model, a U.S. regional model that includes forestry and agriculture sectors with detailed land use categories. Baseline includes the RFS2 mandate without storage costs for cellulosic feedstocks (where corn and miscanthus dominate biofuel production). The scenarios included in the study are introduction of cellulosic feedstock storage costs and introduction of carbon prices. With the introduction of a $\$ 30 / \mathrm{tCO}_{2} \mathrm{e}$ carbon price, the model shows that corn use in ethanol increases and miscanthus use in ethanol decreases. Cellulosic feedstock use shifts to bioelectricity since this shift provides a bigger decline in GHG emissions relative to these feedstocks used in ethanol production. In this scenario, there are significant changes in land use across categories, with a shift toward forestry away from agriculture. In other words, carbon payments encourage a reallocation of land from agriculture to forestry that has higher GHG mitigation potential. The carbon price scenario results in lower GHG emissions. The inclusion of a bioelectricity sector impacts the results significantly, since under the carbon price scenario the option of bioelectricity and its lower GHG 
emissions impact the allocation of feedstocks among alternative uses. The study shows the importance of including spatially explicit land use data as well as including detailed land use categories and transferability across these categories. The significant portion of the GHG mitigation in scenario results comes from afforestation, forest management, and bioelectricity [12•],

In Mosnier et al. [13•], the GLOBIOM model is used to assess the land use and emissions effects of the U.S. RFS2 at a global level. Similarly to FASOMGHG, GLOBIOM proposes a detailed land use representation of agricultural and forestry activities relying on a linear programming approach where allocation decisions are taken to maximize social welfare subject to resource, technological, and policy constraints. Although it operates at the global level, grouping countries into 28 regions, it simulates land use changes at a simulation unit level "defined by the intersection of country boundaries, altitude, and slope and soil classes within a $50 \times 50-\mathrm{km}$ grid." Because of the many similar features between the FASOMGHG and GLOBIOM, this paper offers a strong harmonization regarding key baseline assumptions with the FASOMGHG model, including rates of exogenous crop-yield growth, land conversion for development, and biofuel scenarios. A key result of this study shows that land use emissions are on average 76 times higher in the rest of the world than in the U.S. [13•].

\section{Biofuel Pathways}

The second critical component that impacts GHG emissions is the biofuel pathways used in an economy and included in the model $[10 \bullet, 3]$. All models include firstgeneration biofuels, and only some include secondgeneration biofuels ${ }^{3}$ since commercialization of secondgeneration biofuels is limited at best. The nature of the biofuel pathways included determine which biofuel is the most feasible to meet the demand, the land requirement for that biofuel pathway, and where the additional land will come from.

It should be noted that Khanna and Chen [3] draw attention to the potential of energy crops to sequester carbon in soil. Using crop residues for cellulosic ethanol can affect soil organic matter depending on residue collection rates and tillage practices. They note the importance of providing incentives to produce and sell lower carbon intensity biofuels. An example they provide is the low carbon fuel standard (LCFS) that generated a large implicit subsidy for biofuels with lower carbon intensity [3].

\footnotetext{
${ }^{3}$ Second generation biofuels are ethanol produced from corn stover, wheat straw, switchgrass, miscanthus, or similar energy crops and biodiesel from algae.
}

Among the studies included in this review, Laborde and Valin [10•] include only first generation, crop-based ethanol and biodiesel in the biofuel mix on the EU market. Therefore, in their scenario analyses, EU biofuel targets lead to significant land use change globally. This is either through domestic production of biofuels (domestic feedstocks or imported feedstocks) or through biofuel imports from South America and East Asia to meet NREAP targets [10•].

Sarica and Tyner [14] use the U.S. EPA MARKAL model, a bottom-up energy systems model to analyze the implications of U.S. RFS2 and various biomass technologies. They add two new technologies in MARKAL: biochemical cellulosic ethanol and thermochemical biomass conversion technology. They run U.S. RFS2 scenarios with and without coal combined with biomass technology. Their analysis shows that the inclusion of these technologies in scenarios impacts the results to a significant extent. The results show that introduction of coal combined with biomass technology induces significant increase in thermochemical biofuel production. There is no cellulosic ethanol production in any of the scenario results [14].

Beach et al. [12•] also highlight the fact that whether second-generation biofuel pathways are included in the model or not determine the scenario results and land use allocation. Specifically, their baseline includes the RFS2 mandate without storage costs for cellulosic feedstocks (where corn and miscanthus dominate biofuel production). In the introduction of a cellulosic feedstock storage costs scenario, corn use in ethanol increases and miscanthus use in ethanol production declines. The ethanol feedstock mix responds to the inclusion of storage costs by shifting emphasis to traditional crops with the lowest logistics costs. With storage cost introduction, mix of the crop production changes with little impact on allocation of land use in the U.S. Furthermore, the storage cost scenario results in higher GHG emissions since it has less mitigation potential relative to baseline $[12 \cdot]$.

Chen et al. [15•] and Huang et al. [16] both use the BEPAM model to analyze the implications of U.S. biofuels policy and carbon tax in terms of land use and GHG emissions. BEPAM includes first- and second-generation biofuels, with multiple second-generation biofuel pathways from crop and forest residues, and dedicated energy crops like switchgrass and miscanthus [15•, 16]. Since both models use the same model, the rest of the discussion will be focused on Chen et al. [15•]. The analysis includes a BAU with no biofuel and no carbon policy. They run three scenarios: RFS2, RFS plus cellulosic biofuel producers tax credit, RFS2 plus domestic carbon tax. The inclusion of second-generation biofuels with a detailed land use model allow the authors to analyze implications of a wider range of policy scenarios, as well as the land use and land conversion implications of these policies. With the RFS2 scenario, they find that cellulosic ethanol becomes competitive over time 
with declining processing costs. Cellulosic ethanol meets a significant part of RFS2. The crop area for corn and energy crops increase relative to baseline. The area for energy crops comes from conversion of idle/crop-pasture land and crop area reallocation. They find that RFS2 lowers GHG emissions (domestic plus ILUC). With the introduction of a cellulosic biofuel tax credit to RFS2, cellulosic ethanol production increases further with reduction in firstgeneration biofuel production. This increases not only acreage under bioenergy crops, but also acreage from which crop residues are harvested. GHG emissions decline in this scenario relative to baseline and RFS2. With a carbon tax replacing the cellulosic tax credit, second-generation increases at the expense of first-generation, but to a lesser extent. Crop residue harvest declines since energy crops are used more due to their low carbon intensity. GHG emissions decrease the most in all of the scenarios. The critical part of the model is that the inclusion of multiple biofuel pathways allows the authors to show how GHG emissions depend on the biofuel mix, i.e. the relative role of energy crops which are low-carbon intensity versus crop residues for cellulosic ethanol production. They also depend on the existence of a carbon policy [15॰]. This finding is similar to Beach et al. [12•].

\section{Trade Policy Framework}

The third critical component is the role of trade policy in meeting biofuel targets. Obviously, the trade component is included in all global models. One-country models, like BEPAM, can also include trade through reduced-form equations that imitate global trade response. Although trade plays a role in all models, its role has been identified particularly in Laborde and Valin regarding the EU policy [4]. Although most studies regarding the U.S. RFS2 will point to a potential adjustment in the rest of the world's land use due a decrease in U.S. exports, EU policy will lead to direct and indirect imports affecting different regions, in a heterogeneous way, linking strongly the global LUC pattern to the specific biofuel mix.

Beyond the trade channel, few studies consider the active role of trade policies in shaping the LUC pattern. In particular, Laborde studies not only the role of trade restrictions in the baseline (EU antidumping and countervailing duties on U.S. biodiesel exports, Brazilian ethanol re-exports in Central America and the Caribbean due to trade preferences), but also the effect of trade policy reform in combination with the biofuel mandate [9]. For instance, the same biofuel policy leads to a 1.73 million-ha expansion of global cropland in a scenario with constant trade policy while the combined biofuel policy and the EU removal of trade barriers on ethanol and biodiesel leads to 1.87 million ha.

\section{Uncertainty}

As discussed above, many factors impact land use change from biofuel expansion and the resulting GHG emissions. Zilberman et al. summarize the challenges of computing ILUC as follows: 1. recognizing the heterogeneity of land characteristics, 2. model assumptions on the ease of substitution of land use among different categories, 3. rate of change of agricultural productivity, 4. rate of change of consumer demand, 5. elasticities used in models. Finally, they note the inherent variability of ILUC estimates, though they acknowledge the justification for its use in policy design framework [6].

Of course, the quantification of these different drivers is quite challenging and generates uncertainties. Model components (modeling choices and parameter values) play a significant role in generating variability among the results from model simulations. Thus, different papers consider alternative assumptions to study the uncertainty of their results. Approaches are various: doing sensitivity analysis on one assumption, e.g. alternative value for the exogenous trend in yield productivity, as in Mosnier et al. [13•]; a set of technical or policy parameters, as in Chen et al. and Huang et al. [15•, 16] regarding production costs, yield trends, and land use restrictions; a combination of model closures, technical and behavioral parameters, i.e. elasticities, as in Laborde and Valin [10 ]; or a systemic, but not exhaustive Monte Carlo approach tackling simultaneously eight categories of model parameters in Laborde [9].

As already noted while discussing the challenge of quantifying the ILUC with economic models, uncertainty is a key dimension of both the research and the policy agenda. This uncertainty is not specific to land use change and Rajagopal and Plevin provide a rigorous and systematic approach of the issue considering the different sources of uncertainties: oil market response, non-land-use emissions of producing biofuels, and land-use emissions. They use a Monte Carlo experiment and show that limiting the policy design to add ILUC emissions in the policy's fuel rating systems will not guarantee emissions decline [8].

\section{Computation and Accounting of GHG Emissions}

Since one of the aims of biofuel policies is to reduce GHG emissions, having an exhaustive accounting of the GHG emissions of biofuel production, including, but not limited to land use, is critical.

Most legislative processes on biofuels include GHG emissions, as summarized by Khatiwada et al. [4]. Specifically, they note that the "result of lifecycle GHG emissions varies significantly, depending on the life cycle analysis approach used, type and characteristics of biomass feedstocks, system 
boundaries, functional unit, reference energy systems, conversion technologies, treatment of co-products, direct/indirect land use change". They note that lifecycle GHG emission estimates vary greatly based on agricultural practices $\left(\mathrm{N}_{2} \mathrm{O}\right.$ emissions from applications of nitrogen fertilizer, tillage operations, residue collection and use), land carbon stock, incorporation of direct and indirect LUC, and assumptions in these models regarding land use parameters and electricity credit in the fuel production.

While computing GHG emissions from model simulations, the emission categories included in each study may differ. In some cases, the models focus explicitly on LUC emissions, relying on exogenous and external (legislation, literature) life cycle analysis coefficients to compute the GHG net balance of biofuels, while others have an explicit modeling of non-landuse emissions, considering potential shift in technology (e.g. livestock intensification) as a side effect of the biofuel policy. The emission categories generally included are $\mathrm{CO}_{2}$ emissions from land conversion (due to ILUC) for biomass above ground, mineral carbon in soils, and organic carbon in soil (i.e. peatlands) $[10 \bullet, 12 \bullet, 13 \bullet, 15 \bullet], \mathrm{N}_{2} \mathrm{O}$ from farm inputs and fertilizer [12•, 13•], $\mathrm{CH}_{4}$ from livestock [12•, 13•], and rice production $[10 \bullet, 12 \bullet, 13 \bullet]$. These are included in terms of $\mathrm{CO}_{2}$ equivalent per MJ for policy analysis such as U.S. RFS2 or EU RED.

Similar to Khatiwada et al. [4], Witcover et al. [17] draw attention to the importance of estimating GHG emissions from ILUC in terms of intensity $\left(\mathrm{gCO}_{2} \mathrm{e} / \mathrm{MJ}\right.$ fuel) due to legislation [4, 17]. However, Kauffman and Hayes explore the issue of how to measure GHG emissions in terms of units: per hectare basis (tCO2e/ha) or per energy (gCO2e/MJ) basis and whether the policy implications would change [18•]. In their U.S. model of corn and switchgrass, they incorporate land constraint in a social planner's optimization function to minimize the environmental cost. They find that the optimal solution for which feedstock is chosen depends on the relative energy yield per hectare of corn and switchgrass, carbon price, and external benefits to biofuel production (they measure this by $\$ 0.45$ per gallon biofuel tax credit). They use the EPA's assumptions on annualized GHG emission by biofuel pathway converted to $\mathrm{tCO} 2 \mathrm{e} / \mathrm{ha}$ in their analysis. They show the range of yields where either corn or switchgrass is the optimal choice with and without external biofuel benefits. The measurement of GHG emissions per hectare narrows the gap between corn and switchgrass. This model suggests that if the GHG emissions are measured on a per hectare basis, the ranking between corn and switchgrass may change. The policy design should consider these contrasting findings.

Witcover et al. make an important point that ILUC and GHG emission results are sensitive to policy decisions about the amount of time emissions are tracked after conversion, and how post-conversion emissions are treated (in other words, amortization of emissions annually or assessing them in the year they occur) [17]. In other words, the choice of discount factor and how the intertemporal accounting is performed is significant for GHG accounting. The gains from consuming biofuels will be accumulated over time, year after year, while biomass-based biofuels will replace fossil fuels. On the contrary, most land-use emissions are related to change in land cover and the release of an accumulated carbon stocks, the bulk of them occurring when the conversion is done, or in a relative period of time after (e.g. time for the carbon accumulated in wood from cleared forests to be released). In this framework, the challenge is to balance long-term savings with short-term costs. Most studies will use the ad hoc choices defined in the policy framework to annualize land use emissions. Studies focusing on the EU legislation will use a 20 year period (total land-use emissions are divided by 20 years), while for the U.S. focused studies, a 30-year period is used. More interestingly, O'Hare et al. and de Gorter and Tsur provide a critical discussion on this topic and provide a theoretically sound framework for improved GHG accounting. Both papers show that improved methodology significantly reduces the scope of net GHG savings by many biofuels [19, 20].

\section{Conclusions}

This paper attempts to evaluate the literature published in recent years relevant to ILUC from biofuel expansion and GHG emissions. We showed the variability of ILUC and GHG emission estimates and tried to identify the main sources of variability. These are: a. a level of spatial heterogeneity in the model, b. whether second-generation biofuel pathways are included or not, and c. the role of trade policy. Since design and implementation of biofuel polices have relied on and will continue to rely on simulation models, the variability of these estimates highlights the importance of conducting a comprehensive effort of policy simulation exercises using multiple models. Policy design should acknowledge the underlying uncertainty of these quantitative assessments. In other words, there is no one simulation model that can deliver an answer on ILUC. At the same time, this uncertainty does not mean that policy makers should avoid tackling this critical issue.

Furthermore, policy framework is crucial for development of second-generation biofuels that limit the extent of ILUC, either through consumption mandates or through R\&D grants. Trade policy, though not the first thing that comes to mind when discussing biofuels, has greater implications than is currently acknowledged. Thus, biofuel policy simulation exercises should always be conducted within multiple trade policy frameworks. This also highlights the fact that biofuel policy design should be done in coordination with trade policy design. 
An important point in this debate is made by Beach et al., who note that policy makers can impact only a limited amount of factors [12•]. They show the importance of supply logistics as well as regulation in their simulation results. They note that "the desirability of a given feedstock varies as the set of traits favored by market and policy changes".

It is important to quote Witcover et al. who propose a guideline for policy makers to deal with ILUC and its consequences [17]. These are summarized as (1) use of feedstocks that require less land, (2) adoption of measures that lower LUC risk from land-using feedstocks, and (3) investing in productivity gains and environmental protection.

To sum up, ILUC is a key component of the GHG balance, and the policy design should learn from the assessments based on model simulations, such as the importance of a good trade policy framework, promotion of "some" biofuels vs. others, reinforcement of land conservation programs, defining roadmaps in terms of yields progress and land use achievements, and making the pursuit of biofuels programs contingent to such realization.

\section{Compliance with Ethics Guidelines}

Conflict of Interest Dr. Tokgoz has nothing to disclose.

Dr. Laborde reports grants from Joint Research Center of the European Commission, JRC-ISPRA, and grants from European Commission, DG Trade outside the submitted work.

\section{References}

Papers of particular interest, published recently, have been highlighted as:

- Of importance

1. Searchinger T, Heimlich R, Houghton R, Dong F, Elobeid A, Fabiosa JF, et al. Factoring greenhouse gas emissions from land use change into biofuel calculations. Science. 2008;29:1238-40.

2. Fargione J, Hill J, Tilman D, Polasky S, Hawthorne P. Land clearing and the biofuel carbon debt. Science. 2008;319(5867):1235.

3. Khanna M, Chen X. Economic, energy security, and greenhouse gas effects of biofuels: implications for policy. Am J Agric Econ. 2013;95(5):1325-31.

4. Khatiwada D, Seabra J, Silveira S, Walter A. Accounting greenhouse gas emissions in the life cycle of Brazilian sugarcane bioethanol: methodological references in European and American regulations. Energ Policy. 2012;47:384-97.

5. Khanna M, Zilberman D. Modeling the land-use and greenhousegas implications of biofuels. Clim Chang Econ. 2012;3(3): 1250016.

6. Zilberman D, Barrows G, Hochman G, Rajagopal D. On the indirect effect of biofuel. Am J Agric Econ. 2013;95(5):1332-7.

7. Drabik D, de Gorter H. Biofuel policies and carbon leakage. Ag Bio Forum. 2011;14(3):104-10.

8. Rajagopal D, Plevin RJ. Implications of market-mediated emissions and uncertainty for biofuel policies. Energ Policy. 2013;56:75-82.

9. Laborde D. Assessing the Land Use Change Consequences of European Biofuel Policies, 2011; Technical Report, International Food Policy Research Institute (IFPRI).

10. Laborde D, Valin H. Modeling land-use changes in a global CGE: assessing the EU biofuel mandates with the MIRAGE-BioF model. Clim Chang Econ. 2012;3(3):39. 1250017. The study uses a global CGE model to analyze ILUC and GHG emissions from EU biofuels policy.

11. Golub AA, Hertel TW. Modeling land-use change impacts of biofuels in the GTAP-BIO framework. Clim Chang Econ. 2012;3(3):1250015.

12. Beach RH, Zhang YW, McCarl BA. Modeling bioenergy, land use, and GHG emissions with FASOMGHG: model overview and analysis of storage cost implications. Clim Chang Econ. 2012;3(3):34. 1250012. The study uses a US model to analyze implications of cellulosic feedstock storage costs and introduction of carbon prices.

13. Mosnier A, Havlik P, Valin H, Baker J, Murray B, Feng S, et al. Alternative U.S. biofuel mandates and global GHG emissions: the role of land use change, crop management and yield growth. Energ Policy. 2013;57:602-14. The study uses GLOBIOM, a global PE model, to analyze ILUC and GHG emissions from US RFS2.

14. Sarica K, Tyner WE. Analysis of US renewable fuels policies using a modified MARKAL model. Renew Energy. 2013;50:701-9.

15. Chen X, Huang H, Khanna M. Land-use and greenhouse gas implications of biofuels: role of technology and policy. Clim Chang Econ. 2012;3(3):25. 1250013. The study uses a US model to analyze the implications of cellulosic biofuels producers tax credit and domestic carbon tax.

16. Huang H, Khanna M, Onal H, Chen X. Stacking low carbon policies on the renewable fuels standard: economic and greenhouse gas implications. Energ Policy. 2013;56:5-15.

17. Witcover J, Yeh S, Sperling D. Policy options to address global land use change from biofuels. Energ Policy. 2013;56:63-74.

18. Kauffman NS, Hayes DJ. The trade-off between bioenergy and emissions with land constraints. Energ Policy. 2013;54:300-10. The study uses a US corn and switchgrass model to highlight the role of unit of measurement for GHG emissions for correct policy design.

19. O'Hare M, Plevin RJ, Martin J, Hopson E, Jones AD, Kendall A. Proper accounting for time increases crop-based biofuels' greenhouse gas deficit versus petroleum. Environ Resour Lett. 2009;4: 024001 .

20. de Gorter H, Tsur Y. Cost-benefit tests for GHG emissions from biofuel production. Eur Rev Agric Econ. 2010;37(2):133-45. 